\title{
Correspondence
}

http://dx.doi.org/10.11646/phytotaxa.175.5.10

\section{Draba dongchuanensis (Brassicaceae), a new species from Yunnan, China}

\author{
IHSAN A. AL-SHEHBAZ 1 , JI-PEI YUE ${ }^{2}$, TAO DENG $^{2} \& \mathrm{HONG}$-LIANG CHEN ${ }^{2}$ \\ ${ }^{1}$ Missouri Botanical Garden, P.O. Box 299, St. Louis, Missouri, U.S.A. 63166-0299 \\ ${ }^{2}$ Key Laboratory for Plant Diversity and Biogeography of East Asia, Kunming Institute of Botany, Chinese Academy of Sciences, Hei- \\ longtan, Kunming, Yunnan 650201, People's Republic of China. \\ ${ }^{3}$ Author for correspondence. E-mail: ihsan.al-shehbaz@mobot.org
}

\begin{abstract}
Draba dongchuanensis is described, illustrated, and compared with several, primarily Himalayan and Tibetan species, including D. amplexicaulis, D. draboides, D. mongolica, D. polyphylla, D. setosa, and D. surculosa. From these, it is readily distinguished from all of the Himalayan species of Draba by a combination of strongly dilated filament bases, setose basal leaves, and auriculate middle cauline leaves.
\end{abstract}

Keywords: Cruciferae, Draba, Himalayas, Tibetan Plateau.

Draba L. is the largest genus in the Brassicaceae (Cruciferae) and includes over 400 species (Al-Shehbaz 2012b). The Hengduan Mountains and Tibetan Plateau represent one the major diversity centers of the genus, where at least 52 species grow (Jordon-Thaden et al. 2013). The account of Draba for the Flora of China (Zhou et al. 2001) included 41 species in the Sino-Himalayan parts of Qinghai, Sichuan, Xizang, and Yunnan provinces. Since then, the ranges of several species were expanded and eight new species have been added (Al-Shehbaz 2002, 2004a, 2004b, 2006, 2012). With the novelty below, the Sino-Himalayan region currently includes 52 species, of which 19 occur in Yunnan, 21 in Qinghai, 24 in Sichuan, and 39 in Xizang (Tibet).

During a recent visit to the Kunming Institute of Botany (Yunnan, China) by one of us (IAS) to work on the Sino-Himalayan Brassicaceae (Cruciferae), especially the genus Draba, a new species of Draba was discovered. It is described below, and its relationships to nearest relatives are discussed.

Draba dongchuanensis Al-Shehbaz, J.P.Yue, T.Deng \& H.L.Chen, sp. nov. Type:-CHINA. Yunnan: Dongchuan, Shekuai Xiang, $26^{\circ} 09^{\prime} 21.5^{\prime \prime} \mathrm{N}, 102^{\circ} 55^{\prime} 40.2^{\prime \prime} \mathrm{E}, 4020 \mathrm{~m}, 18 \mathrm{Jul}$ 2009, alpine meadow, Ende Liu \& Wei Fang 2105 (holotype, KUN; isotype, KUN). Figure 1.

Herbs perennial, cespitose; caudex slender, few branched, covered with petiolar remains of previous years, ultimate branches terminated in rosettes. Stems $8-13 \mathrm{~cm}$ tall, erect, simple above, several branched basally, hirsute proximally with a mixture of simple trichomes $0.4-1.0 \mathrm{~mm}$ mixed with appressed, subsessile, 2- or 3-rayed, much smaller trichomes, subtomentose distally with appressed, mostly 2-rayed trichomes mixed with fewer simple ones. Basal leaves rosulate, sessile; leaf blade obovate or oblanceolate to narrowly oblong, 5-10 $\times 2.0-2.5 \mathrm{~mm}$, hirsute abaxially mainly with simple trichomes $0.7-1.0 \mathrm{~mm}$ sometimes mixed with fewer, smaller, stellate, 4-rayed trichomes, subglabrous adaxially, sometime distally with simple trichomes, margin entire, setose-ciliate with simple trichomes $0.8-1.5 \mathrm{~mm}$, apex obtuse; cauline leaves 5-8, sessile, oblong to oblong-lanceolate, middle ones 7-13 $\mathrm{mm} \times 1.5-2.8 \mathrm{~mm}$, pubescent as basal leaves, base minutely auriculate, upper ones narrower, not auriclate at base. Racemes 6-30-flowered, with lowermost one or two flowers bracteate, elongated considerably in fruit; rachis straight, pubescent; middle and lowermost fruiting pedicels $8-12 \mathrm{~mm}$, divaricate, gently curved upwards, pubescent abaxially with subsessile, forked or substellate trichomes mixed with fewer simple ones, glabrous adaxially. Sepals yellow, broadly ovate, 1.8-2.5 $\mathrm{mm}$, ascending, sparsely pubescent abaxially, base of lateral pair slightly saccate, margin membranous; petals yellow, obovate, 3-4 × 1.5-2.0 mm, apex emarginate; claw to $0.5 \mathrm{~mm}$; filaments yellow, subequal, $1.5-2.0 \mathrm{~mm}$, strongly dilated at base; anthers ovate, $0.3-0.4 \mathrm{~mm}$; ovary glabrous; ovules $4-8$ per ovary. Fruit lanceolate-linear, $7-10 \times$ 
Only three other Sino-Himalayan species of Draba (D. amplexicaulis Franchet (1886: 403), D. polyphylla Schulz (1927: 180), and $D$. surculosa Franchet (1886: 401), have a combination of yellow flowers, basally bracteate racemes, and auriculate cauline leaves. From these, $D$. dongchuanensis is easily distinguished by having coarsely setose (vs. non-setose) leaves, in addition to the strongly dilated (vs. slender) filament bases.

Draba dongchuanensis resembles D. setosa Royle (1834: 71), a species of scree and gravelly mountain slopes (Afghanistan, China (Xizang), India, Pakistan), in having setose-ciliate basal leaves subglabrous adaxially, obovate yellow petals emarginate at apex, and latiseptate fruits similar in size, shape, and style length. However, the novelty differs from $D$. setosa by its strongly dilated (vs. slender) filament bases, obovate or oblanceolate to narrowly oblong (vs. linear to linear-oblong) basal leaves with obscure (vs. prominent) midvein abaxially, non-scapose (vs. scapose) plants with 5-8 (vs. 0 or rarely 1 ) cauline leaves, 4-8 (vs. 12-16) ovules per ovary, and slightly narrower fruits 2-2.5 (vs. $2.5-3.5$ ) $\mathrm{mm}$ and broader seeds $1.5-2 \times 0.7-1$ (vs. $1-1.4 \times 0.6-0.7) \mathrm{mm}$.

Plants of Draba dongchuangensis grow in the same general area and can be confused with those of D. mongolica Turczaninow (1842: 256), especially when have fully mature fruits. However, the latter grows on alpine rocky slopes and crevices (vs. alpine meadows) and is a very widespread species in China (Gansu, Hebei, Heilongjiang, Jilin, Nei Mongol, Qinghai, Shaanxi, Shanxi, Sichuan, Xinjiang), Mongolia, and Russia. The new species can easily be distinguished by its yellow (vs. white) petals, coarsely setose (vs. minutely tomentose) basal leaves, 4-8 (vs. 6-17 cauline leaves, strongly dilated (vs. slender) filament bases, and 4-8 (vs. 12-20) ovules per ovary.

\section{Acknowledgements}

We are profoundly grateful to Professor Hang Sun of his support throughout our studies of the Sino-Himalayan Draba. We thank the National Natural Science Foundation of China for the grant NSFC-31170181 to J. P. Yue that supported the research and fieldwork on Draba, as well as the National Science Foundation of the United States for the grant DEB-1252905 to Al-Shehbaz for supporting his research on the Brassicaceae.

\section{References}

Al-Shehbaz, I.A. (2002) Six new species of Draba (Brassicaceae) from the Himalayas. Novon 12: 314-318. http://dx.doi.org/10.2307/3393072

Al-Shehbaz, I.A. (2004a) Novelties and notes on miscellaneous Asian Brassicaceae. Novon 14: 153-157.

Al-Shehbaz, I.A. (2004b) Two new species of Draba (Brassicaceae): D. mieheorum from Tibet and D. sagasteguiii from Peru. Novon 14: 249-252.

Al-Shehbaz, I.A. (2007) Two new species of Draba and Eutrema (Brassicaceae) from Sichuan, China. Harvard Papers in Botany 11: $277-279$.

http://dx.doi.org/10.3100/1043-4534(2007)11[277:tnsoda]2.0.co;2

Al-Shehbaz, I.A. (2012a) Two new species of Draba (Brassicaceae): D. cajamarcensis from Peru and D. jiulongensis from China. Rhodora 114: $31-36$ http://dx.doi.org/10.3119/0035-4902-114.957.31

Al-Shehbaz, I.A. (2012b) A generic and tribal synopsis of the Brassicaceae (Cruciferae). Taxon 61: 931-954.

Franchet, A. (1886) Plantas yunnanensis a cl. J. M. Delavay collectas. Bulletin de la Société Botanique de France 33: 358-467. http://dx.doi.org/10.1080/00378941.1886.10828470

Jordon-Thaden, I.E., Al-Shehbaz, I.A. \& Koch, M.A. (2013). Species richness of the globally distributed, arctic-alpine genus Draba L. (Brassicaceae). Alpine Botany 123: 97-106. http://dx.doi.org/10.1007/s00035-013-0120-9

Maximowicz, C.F. (1880) Diagnoses plantarum novarum asiaticarum. III. Scripsit. Bulletin de l'Acadmie Impériale des Sciences de St.Pétersbourg 26: 420-452.

Royle, J.F. (1934) Illustrations of the Botany and Other Branches of the Natural History of the Himalayan Mountains and of the Flora of Cashmere, vol. 1. William H. Allen and Co., London. http://dx.doi.org/10.5962/bhl.title.449

Schulz, O.E. (1927) Cruciferae-Draba et Erophila. In : Engler, A. (Ed) Das Pflanzenreich, 89(IV. 105). Verlag von Wilhelm Engelmann, Leipzig, pp 1-396.

Turczaninow, N.S. (1842) Flora baicalensi-dahurica seu descriptio plantarum in regionibus cis- et transbaicalensibus atque in Dahuria sponte nascentium. Bulletin de la Société impériale des Naturalistes de Moscou 15: 223-313. http://dx.doi.org/10.5962/bhl.title.6632

Zhou, T.-Y., Lu, L.-L., Yang, G. \& Al-Shehbaz, I.A. (2001) Brassicaceae. In: Wu, C.-Y. \& Raven, P.H. (Eds) Flora of China, vol 8. Science Press (Beijing) and Missouri Botanical Garden (St. Louis), pp. 1-193. 